\title{
Filosofía Estratégica de la Empresa
}

\author{
Prof. Juan PUELL PALACIOS
}

La finalidad de las empresas es ofrecer bienes y servicios a la sociedad para satisfacer sus necesidades y deseos, y mejorar sus condiciones y calidad de vida. Como sabemos los, objetivos de un empresario es saber sobrevivir frente a los cambios, a las crisis, a las fluctuaciones constantes de los mercados, la rentabilidad del dinero invertido, así como una posición de competitividad en el entorno empresarial ¿Qué tiene que ver todo esto con la filosofía? ¿Qué tiene que ver la filosofía con la empresa?

Los empresarios, así como los gobernantes, tienen pués la función de ser maestros, filósofos, procurando el bienestar de la sociedad a través de los usuarios, en otras palabras, les corresponde mejorar a la gente y de ese modo mejorar la vida social.

Por cierto que podemos relacionar a la filosofía y a la estrategia de la empresa a través de la cultura empresarial que está representada en su seno por sus valores, normas, que aseguran una convivencia en armonía y equilibrio con la sociedad interna y externa; sus costumbres, usos, la manera de hacer las cosas, el modo de ser de la empresa ante la comunidad, y también de su marca y símbolos, publicidad, promoción, el prestigio que tiene en la sociedad, así como el que les da a sus ejecutivos y a su personal.

El concepto de cultura empresarial tiene mucho de lo que es la filosofía de la empresa. La cultura empresarial no solo está compuesta de los valores, normas, costumbres, usos y símbolos, sino también los de cada persona que forma parte de su estructura, sobresaliendo su inteligencia, su moral, su racionalidad, su ejemplo.

\section{CONCETUALIZACIÓN DE LA FILOSOFÍA ESTRATÉGICA DE LA EMPRESA}

A la empresa no sólo debemos observarla para comprenderla y entenderla, sino que debemos cambiarla y transformarla para llevarla a un nivel de competitividad superior. La filosofía estratégica de la empresa la podemos definir de la siguiente manera: 
- La relación de la empresa con su medio ambiente o entorno para sobrevivir o adaptarse a los cambios positivos o negativos

- Que es lo que espera la empresa de la comunidad y que es lo que espera la comunidad de la empresa, manteniendo un equilibrio y relación armoniosa, la filosofía aclara las proposiciones y la ciencia las verifica, una busca la verdad y la otra lo comprueba.

- La cultura empresarial debe estar relacionada con el entorno interno y externo asegurando una satisfacción recíproca y un beneficio compartido, con la cordialidad, respeto y armonía. Existen muchas necesidades sociales que todavía están ocultas y es función de la filosofía estratégica encontrarlas y convertirlas en nuevos bienes o servicios.

\section{CARACTERÍSTICAS DE LA FILOSOFÍA DE LA EMPRESA}

Desde un punto de vista pragmático y económico la estrategia de la empresa ofrece cuantitativamente metas y cualitativamente objetivos. En primer lugar, desde el punto de vista filosófico la empresa se relaciona con la comunidad generando oportunidades de empleo para proporcionar mayor bienestar social y económico a los habitantes de una colectividad que tengan el perfil idóneo para determinados trabajos.

Esta relación se extiende a los clientes y proveedores para buscar un beneficio mutuo, esto implica una responsabilidad social compartida para desarrollarse y crecer como una negación del pasado a favor del futuro. El futuro de la empresa depende de la calidad de su gente, este se construye, no se espera.

En segundo lugar, en la relación de la empresa y su entorno debe haber una reciprocidad de beneficios mutuos respetando lo que nos ofrece la naturaleza y disfrutando de ella al mismo tiempo, al final esta es la filosofía esencialmente empresarial. En este sentido la filosofía viene a ser el esfuerzo de elevar a la empresa hacia el saber y el conocimiento con toda la capacidad y experiencia de su gente. En tercer lugar, la filosofía empresarial debe ser redactada en forma sencilla, clara y práctica para exponer sus valores, creencias y ofrecimientos a la comunidad, a los accionistas y a su personal, y lo que la empresa le solicitará a ellos. El recurso humano de la empresa es la piedra angular que la sostiene. Por ello la empresa debe ofrecerles desarrollo en sus carreras profesionales a través de la capacitación permanente para adquirir nuevos conocimientos, sueldos justos y una buena calidad de vida, a cambio la empresa pide mayor productividad individual, lealtad, convicción y buen desempeño en sus labores. En cuarto lugar, al igual que la visión empresarial, la filosofía estratégica de la empresa debe ser definida por los dueños de la misma por las siguientes razones. 
La filosofía debe nacer del corazón de los que formaron la empresa, porque ella constituye una causa y un compromiso con su entorno interno y externo.

- La filosofía viene de generación en generación evolucionando en respuesta a los cambios de la realidad económica, política y social, y los dueños actuales deberán perpetuarla, si es que con el tiempo ha dado buenos resultados.

- La permanencia del personal que labora en la empresa es temporal, y cuando tenga que irse adoptará un cambio en la propia filosofía.

En quinto lugar, ¿cada cuánto tiempo debe definirse o redefinirse la filosofía estratégica de la empresa?. De acuerdo a esta posición estaríamos pensando que la filosofía tiene un período de caducidad, pero la respuesta es que no tiene exactamente un período de cumplimiento como la visión o la misión. En la filosofía estratégica de la empresa no se definen sueños ni grandes metas sino conceptos filosóficos de como relacionarse mejor con el entorno interno y externo, y estos conceptos se desprenden y vienen de las pasiones de los que crearon el negocio, y es por esta razón que la filosofía estratégica de la empresa no puede cambiarse sin que exista ninguna racional justificación. Sin embargo esta podrá cambiar sólo si se presentan dos elementos que la impacten:

1. Cuando la filosofía estratégica de la empresa ya no responda a los cambios actuales del entorno. Los fenómenos sociales, las crisis económicas, las condiciones del mercado, los avances tecnológicos y científicos traen cambios que obligan a que la filosofía de la empresa se tenga que adaptar a estos cambios.

2. Las generaciones que administran ahora el negocio, que descienden de los dueños originales, consideran que los tiempos han cambiado y se hace necesario, un cambio o modificación de la filosofía. Esta misma situación se va a presentar a las futuras generaciones de los que ahora tienen a su cargo la gestión del negocio. Es recomendable que la filosofía estratégica de la empresa dure lo que tenga que durar y que cambie cuando tenga que cambiar.

En sexto lugar, el éxito de haber elaborado una filosofía estratégica de la empresa, no es suficiente para que tenga mayores niveles de competitividad y sobrevivencia en el mercado, sino que los líderes, directores, ejecutivos, asesores, profesionales, jefes de departamentos o unidades orgánicas deberán seguirla de manera cabal, demostrar al personal y a la comunidad que la empresa cumple con lo que se compromete ante su comunidad. . Solamente el compromiso que asume la empresa con la comunidad le dará su más puro sentido filosófico y esto permitirá que la gente con la que tiene contacto crea en ella, de lo contrario, no sería posible si los dueños y los ejecutivos no la ponen en práctica. 


\section{CLASIFICACIÓN DE LA FILOSOFÍAESTRATÉGICAEMPRESARIAL}

Cada empresa tiene su propia filosofía, es decir, difícilmente puede haber varias empresas que tengan la misma filosofía estratégica. Es preciso señalar que la filosofía estratégica de la empresa debe tener una clasificación amplia que comprenda tanto el entorno en general y todo aquello que tenga relación con la empresa. En la figura siguiente se muestra una clasificación de la filosofía estratégica de la empresa.

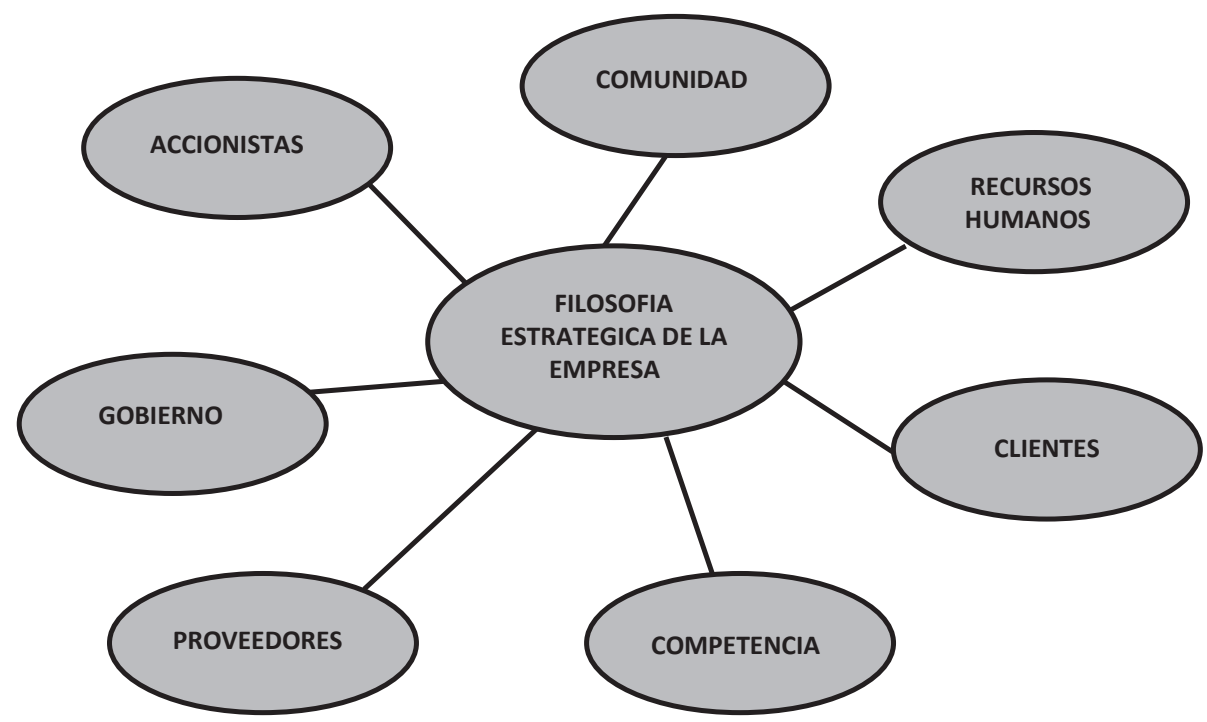

Clasificación de la filosofía estratégica de la empresa

La filosofía empresarial ayuda a que la gestión a los gerentes sea inteligente, positiva y pragmática. Significa también conocer sus propias fortalezas y debilidades. De acuerdo a la clasificación de la filosofía estratégica de la empresa, ésta debe definirse en dos sentidos: 1) ¿Qué puede ofrecer la empresa al personal? 2) ¿Qué puede requerir la empresa al personal? Esto implica que la filosofía estratégica de la empresa está dirigida tanto al interior como al exterior, tal como se puede apreciar en la siguiente tabla:

\begin{tabular}{|c|c|}
\hline INTERNO & EXTERNO \\
\hline $\begin{array}{l}\text { 1. Accionistas } \\
\text { 2. Recursos Humanos o personal }\end{array}$ & $\begin{array}{l}\text { 3. Clientes } \\
\text { 4. Proveedores } \\
\text { 5. Competencia } \\
\text { 6. Comunidad } \\
\text { 7. Gobierno }\end{array}$ \\
\hline
\end{tabular}


Trataremos de explicar cada uno de estos elementos de la filosofía estratégica de la manera más sencilla para entenderlos y comprenderlos y nos permita orientar los cambios de la empresa para satisfacer eficientemente a cada uno de ellos:

\section{Que puede ofrecer la empresa al personal.}

Este elemento del entorno interno dentro de la clasificación de la filosofía estratégica empresarial, es el que marca la diferencia entre una empresa y otra, por su talento, su desempeño y trato al cliente, da el sello distintivo, ese por el cual los clientes profieren una empresa de otra.

La empresa les ofrece una fuente de empleo, desarrollo personal, buen ambiente de trabajo, lealtad y respeto, compensaciones justas, buen trato, amistad y compañerismo, estabilidad y seguridad, participación compartida. A cambio la empresa requiere de su personal: honestidad y respeto, lealtad, trabajo en equipos, actitud abierta, apoyo incondicional, identificación con la misión, sentido de respeto, etc.

\section{Que puede ofrecer la empresa a los clientes.}

Es una de las partes del entorno externo, porque gracias a ellos la empresa sobrevive. Es un elemento vital de la filosofía de la empresa y del entorno para cualquier organización. Lo esencial de la filosofía estratégica de la empresa es satisfacer sus necesidades, a cambio de un negocio rentable para ambos, es decir, tu ganas yo gano, al final todos ganamos desde el punto de vista de la filosofía estratégica, la empresa puede ofrecerle a los clientes, productos y/o servicios de calidad, a precios razonables y un buen servicio de postventa, abastecimiento en el mercado, lealtad en nuestra relación, productos que no contaminen el medio ambiente, puntualidad y oportunidad en la entrega de productos, un buen trato aún en tiempos difíciles, entre otros aspectos.

\section{Que puede ofrecer la empresa a los proveedores.}

De acuerdo a la concepción de la filosofía estratégica de la empresa, los proveedores son los que abastecen con los insumos o materias primas a las empresas que se encuentran en el sector industrial, comercial y de servicios. La empresa puede ofrecerles a los proveedores una relación que beneficie a ambos, en este sentido la empresa puede ofrecerles; puntualidad en los pagos, considerarlo como un aliado y socio del negocio, parte esencial en la cadena de suministros, una relación basada en la honestidad, transparencia, lealtad, cordialidad, desarrollo y entrenamiento en el manejo de productos.

\section{Que puede ofrecer a la competencia.}

La competencia es una parte de la filosofía estratégica de la empresa que 
también está integrada a la parte externa del entorno, y es importante porque permite evaluar la filosofía. No se debe temer a la competencia, hay que temerle a la incompetencia. Si evaluamos nuestra filosofía estratégica de la empresa debemos tener en cuenta si se trata de una competencia directa o indirecta.

La competencia nos permite analizar en qué situación estamos en el mercado y de acuerdo a esto la empresa les puede ofrecer: Una relación respetuosa y cordial, aprender de ella en lo que ambos hacemos, reconocer que estamos en ventaja,o desventaja, en casos de contingencia podemos coordinar esfuerzos para satisfacer a nuestros clientes y lograr buenos resultados, demostrar que somos mejores que ella en calidad, precios y servicios; reconocer que la diferencia entre ella y nosotros es la gente, por eso seremos los mejores.

ESTRATEGIA DE LA EMPRESA

\section{Que puede ofrecer la empresa a la comunidad.}

La comunidad en la filosofía estratégica de la empresa se refiere a la localidad donde está instalada la empresa. Esta comunidad está integrada por los vecinos que viven en esa localidad, por escuelas, calles, iglesias, parques, hospitales, y representantes de organizaciones. Esto constituye una realidad social cuya estructura política se denomina sociedad. 
En esta relación con la comunidad, la empresa le puede ofrecer: colaborar con la limpieza de la ciudad para una mejor calidad de vida, contribuir con la salud de la población en coordinación con los hospitales, colaborar en la construcción de asilos para ancianos para garantizarles una vida digna, apoyar en la seguridad y alumbrado público, construir un centro de desarrollo e integración social para los discapacitados, entre otras cosas.

\section{Que puede ofrecer la empresa al gobierno.}

¿Por qué se tiene que considerar el gobierno como parte de la filosofía estratégica de la empresa? Existe una relación entre el gobierno y la empresa en el sentido de que las empresas tienen que cumplir con las leyes que él establece. Pero existen programas sociales, que no están normados que desarrolla el gobierno, y requiere una coordinación con las empresas. La empresa que está localizada en una comunidad se vincula con el gobierno en tres niveles; Gobierno Nacional, gobierno Regional y Gobierno Municipal. Entre lo que la empresa le puede ofrecer al gobierno podemos mencionar: El cumplimiento de sus obligaciones, apoyo a los programas sociales, construcción de escuelas y universidades, mantenimiento de la salud pública, apoyar al servicio público de los bomberos, mejorar la seguridad social, apoyo a los adultos de la tercera edad.

\section{Que puede ofrecer la empresa a los accionistas.}

Los accionistas, de acuerdo a la filosofía estratégica de la empresa forma parte del entorno interno al igual que el personal de la empresa. Ellos son los principales protagonistas, porque si ellos no existieran y no aportaran sus capitales, el negocio no existiría. En una compañía puede haber dos tipos de accionistas o socios: Los accionistas o socios capitalistas que son aquellos que aportan sus capitales y/o sus recursos como tecnología o maquinarias, materias primas, etc. Y los accionistas o socios industriales o intelectuales, que son los que invierten conocimientos, habilidades o experiencias para hacer crecer el negocio y hacerlo cada vez más próspero y competitivo. En este caso, siempre se plantea la pregunta ¿qué esperan los accionistas del negocio?, la respuesta es la siguiente: Beneficios económicos razonables, satisfacciones personales cuando evalúan la gestión del negocio, apoyar a la familia, posibilidades altruistas, una fuente de trabajo para si mismo, en síntesis podemos decir que los accionistas buscan mayor independencia y libertad en su vida personal.

\section{BIBLIOGRAFÍA}

* Sergio Luis Naumov Garcia: Organización Total,Editoria 1Mc GrawHill-2011. 
* Blanchard Ken y Michael O connor: Administración por valores. Editorial Norma-1997.

* Fernandez Arena,Jose'Antonio:El Proceso Administrarivo. Editorial Diana-1977.

* Bob Tricker: Dirección Corporativa. Editorial Nueva Economía-2010.

* Thomas O. Davenport: Capital Humano. Editorial Deusto-2006.

* Gareth R.Jones: Teoría Organizacional. Editorial Prentice Hall-2008.

* Jaime Barylco: La Filosofía. Editorial Planeta 2005.

Lima,Junio 2012 